Article

\title{
Public Acceptability of Introducing a Biogas Mandate in Korea: A Contingent Valuation Study
}

\author{
Ho-Young Kim, So-Yeon Park and Seung-Hoon Yoo * \\ Department of Energy Policy, Graduate School of Energy \& Environment, Seoul National University of Science \\ \& Technology, 232 Gongreung-Ro, Nowon-Gu, Seoul 01811, Korea; sksflyh@seoultech.ac.kr (H.-Y.K.); \\ imsyeon@seoultech.ac.kr (S.-Y.P.) \\ * Correspondence: shyoo@seoultech.ac.kr; Tel.: +82-297-068-02
}

Academic Editor: Doug Arent

Received: 5 July 2016; Accepted: 12 October 2016; Published: 25 October 2016

\begin{abstract}
Biogas (BG), a renewable form of energy, can mitigate greenhouse gas emissions, unlike conventional gas. Thus, the Korean Government is considering the introduction of a BG mandate, in which the legal blend is $2 \%$ BG and $98 \%$ conventional gas (BG2), by 2020 to expand BG use. We should examine the public acceptability of the introduction, which will incur a rise in the gas price. This study attempts to assess the public's willingness to pay (WTP) for introducing the BG2 program in Korea. The WTP data were obtained from a one-and-one-half-bounded dichotomous choice contingent valuation survey of 1000 households. Because a considerable number of the respondents $(63.4 \%)$ gave a zero WTP response, we applied a spike model to treat the WTP data with zero observations. The yearly mean WTP was computed as 2539 Korean won (KRW) (USD 2.5) per household for the next 10 years, which is also statistically meaningful at the $1 \%$ level. Expanding the value to the national population gives us KRW 50.7 billion (USD 49.5 million) per year. The present value of the total public WTP amounts to KRW 372.7 billion (USD 368.4 million) using a social discount rate of $5.5 \%$. We can conclude that gas consumers in Korea are ready to shoulder some of the financial burden of expanding the use of BG.
\end{abstract}

Keywords: biogas; public acceptability; contingent valuation; willingness to pay; spike model

\section{Introduction}

The amount of greenhouse gases (GHGs) in the atmosphere has increased since the Industrial Revolution as a result of various human activities. Carbon dioxide $\left(\mathrm{CO}_{2}\right)$ is the GHG most commonly produced by human activities, and it is to blame for $64 \%$ of global warming. Currently, the $\mathrm{CO}_{2}$ concentration in the atmosphere is $40 \%$ higher than before industrialization. This phenomenon occurred as a result of the combustion of fossil fuel, and the use of fossil fuel entails many problems, such as finite resources and atmosphere pollution. In contrast, renewable fuels, such as biofuel, wind power, solar energy, and waste energy, can significantly mitigate GHG emissions and air pollutants. Because of this, biofuel is considered to be a viable alternative fuel. The reduction in GHG emissions resulting from the use of biofuel and biofuel blends has been implemented as a policy in several countries following the "Direct Action" approach to climate change.

Therefore, the global production of biofuel has been steadily growing. In particular, many countries have focused on biogas (BG) in their adoption of alternative fuel as a substitute for conventional gas. BG is a gas that is formed by anaerobic micro-organisms and considered to be a renewable fuel. The anaerobic digestion is active in landfills where they are the principal process degrading landfilled food wastes. BG is produced out of this process. The process occurs in an anaerobic (oxygen-free) environment through the activities of acid- and methane-forming bacteria that break down the organic material and produce methane and $\mathrm{CO}_{2}$ in a gaseous form known as $\mathrm{BG}$. 
Such BG can be collected and used as a potential energy resource [1]. BG has environmental merits; for instance, it can be produced from various waste sources, including landfill material, animal manure, waste water, industrial waste, and commercial organic waste [2]. Moreover, BG can have an affirmative influence on the air quality due to the reduced GHG emissions from the use of fossil fuels. In the case of BG produced on a dairy farm, it can provide a good opportunity for increasing the farm's income [3]. For this reason, many countries have recently tried to establish a policy or program related to BG.

The EU has set renewable energy goals as part of its effort to achieve a low-carbon society. It plans to produce about $20 \%$ of the total energy consumption from renewable sources by 2020 . To achieve this goal, several countries of the EU have introduced biofuel. The United States has implemented its 'Renewable Fuel Standard' (RFS), which is an environmental policy to supply fuel blended $(9.74 \%, 2013)$ with biofuel [4]. This policy is an effort to reduce greenhouse gas emissions and expand the nation's renewable fuel sector while reducing its reliance on imported oil. As a result, the BG consumption has increased up to six times compared with that of the early 2000s. The RFS has laid the basis for the biofuel industry and one of the most glittering energy policies in the United States. In the United Kingdom, at least $2.5 \%$ of biofuel must be blended with gasoline or diesel, and there are plans to replace $5 \%$ of all general fuel with biofuel. The German Government established a policy for an "integrated energy climate change package" (Integrated Energy and Climate Program). The policy provided the total solution to reduce carbon dioxide and to deal with global climate-energy problems $[5,6]$.

The Korean Government has focused on investing in research and development to make a policy for expanding the use of biofuel. The Korean Government is also considering the introduction of an RFS. It is a mandate to blend biofuel with conventional fuel. For the BG mandate, it is suggested that $2 \%$ BG and $98 \%$ conventional gas (BG2) be legally blended by 2020 . Moreover, the Korean Government has announced a plan to produce BG (655 thousand tons per day) that can refuel 22 thousand cars by investing about 14,617 billion Korean won (KRW) (USD 14.4 billion) by 2025. In this way, the Korean Government is trying to implement a policy expanding the use of BG. Through this BG policy, Korea would enjoy a reduction in GHG emissions, a decrease in air pollutant emissions, an increase in energy security from reducing the crude oil imports from abroad, and the creation of new jobs related to BG production and distribution. However, this policy could have rebound effects such as an increase of overall energy production and consumption, a loss of jobs in conventional fuel sectors, and so on.

If the BG2 policy is adopted, costs of the policy will be incurred now, with the expectation that inhabitants in Korea will reap the ensuing benefits. Employing economic efficiency as the sole criterion, the BG2 policy should be evaluated in a conventional cost-benefit analysis context. In other words, policy implications of whether to introduce the BG2 mandate could, in principle, be deduced from an examination of costs and benefits associated with such an introduction. Moreover, an important first step in fostering a productive debate over the mandate to reduce GHG emissions is a better understanding of its benefits and costs. The BG policy will raise the production cost of fuel, and consumers will consequently experience a rise in the price of gas if gas demand is not perfectly elastic with respect to its price change. In order to make an informed public decision, some information on the economic benefits would be useful. This study addresses a component of the benefits that such an analysis would consider: the public acceptability or benefits of the BG2 policy. Some studies related to biofuel can be found in the literature. These studies were conducted to assess the premium for or external benefits of bioenergy and to obtain some information about consumers' preferences. Interestingly, most of the studies [7-13] measured the economic value of bioenergy using the contingent valuation (CV) method. For example, Hite et al. [7] examined the willingness to pay (WTP) a premium for electricity generated from biomass and obtained a mean additional WTP estimate of about USD 5.73 per household per month in the US. Soliño et al. [8] investigated the data obtained from a survey of Spanish households aimed at measuring their WTP a premium for electricity generated from biomass. The mean additional WTP was estimated to be about EUR 38 (USD 53.1) per household per year in Spain. Solomon and Johnson [9] and Petrolia et al. [10] estimated the WTP a premium for biomass ethanol in the US. The WTP a premium for biomass ethanol was computed to be about USD 
0.4 per gallon as a fuel surcharge in Solomon and Johnson's paper [9]. Petrolia et al. [10] found a mean WTP a premium for biomass ethanol of about USD 0.12 to 0.15 per gallon of gasoline surcharge. Savvanidou et al. [11] elicited the WTP for biofuel and found that the mean WTP a premium amounted to EUR 0.06 to 0.08 (USD 0.08 to 0.11 ) per liter of biofuel surcharge in Greece. Cicia et al. [12] measured the WTP a premium for the generation of biomass power as about EUR 40.06 (USD 56.1) per household bi-monthly in Italy. Lanzini and Testa [13] conducted a survey regarding biofuel in Italy. Moreover, this study examined consumers' WTP a premium for biofuel, and most respondents reported their additional WTP as being up to EUR 0.14 (USD 0.20). In summary, there are many CV studies on WTP for biofuel, but the CV studies on BG, in particular, remain scarce.

As shown above, many studies have examined consumers' WTP a premium for biofuel by employing the CV method, one of the most popular methods used by environmental and resource economists to value environmental and non-market goods. We can find various pieces of empirical evidence in the literature showing that people are willing to pay a premium for biofuel. Therefore, our strategy of applying the CV method to investigating the public acceptability of introducing the BG2 mandate is consistent with the practices of former studies. We attempt to elicit the public's additional willingness to pay (WTP) for BG2 instead of conventional gas by using a CV approach to analyze the data on WTP. The remainder of the paper is made up of four sections. The methodology adopted in this study and the data used are explained in Section 2. Section 3 describes the WTP model used. The empirical results are reported and discussed in Section 4, and the paper is concluded in Section 5.

\section{Methodology}

\subsection{Object to Be Valued}

The object to be valued in this study is obviously the dollar value of the public acceptability for consuming BG or a premium for BG over conventional gas. More specifically, we assess the governmental policy of introducing the BG2 mandate until 2020 to expand the use of BG. The main instruments for achieving the improvement goal for the proposed policy include the following:

- a blend of $2 \%$ BG for gas-supplying companies;

- improving the system of gathering and reusing waste resources to increase their use; and

- financially supporting the research and development of technology for the low-cost production of BG.

The expected effects of the policy implementation are summarized fourfold. First, the BG2 mandate will contribute to the reduction of GHG emissions. Second, the use of BG from domestic sources will improve the trade balance, because most of the gas consumed in Korea is imported from abroad. Third, the use of BG from domestic sources will reduce Korea's energy dependency and increase the supply security of fuels. Fourth, the BG2 mandate will stimulate the research and development of less costly BG production and create new jobs. These effects, as well as the BG2 policy, were explicitly conveyed to the respondents during the survey.

\subsection{The Method of Investigating the Public Acceptability of Introducing a BG Mandate}

In the context of economics, the consumption benefits of a commodity are defined as the area below the demand curve for the commodity. The area is precisely consumers' WTP for the commodity. Thus, we can usually value the benefits by first estimating the demand function and then computing the area. However, if the commodity is not traded in the market-in other words, it is a non-market good-estimating the demand function will be difficult. In this case, the area can be directly computed by using a stated preference technique such as the $C V$ method $[14,15]$ rather than estimating the demand function and then calculating the area under it. In our study, the demand function is defined for environmental quality improved by the BG2 policy implementation. The expansion of BG use is a case for which directly calculating the area under the demand function is an appropriate strategy. 
Therefore, we estimate the WTP for the environmental quality improvement through the BG2 policy implementation using the $\mathrm{CV}$ technique.

The CV technique has been very widely applied in the literature to obtain the WTP for non-market goods [16,17] and environmental goods [18-33]. Refer to Carson and Hanemann [34] for a better understanding of the CV technique and its implementation. There are no restrictions on the objects that can be valued using the CV method. In particular, it is more useful than other methods because it can capture the non-use or existence value of goods, which cannot be measured through the market mechanism. Non-market goods include environmental goods or public goods, such as the expansion of BG use. Thus, as explained earlier, this study seeks to utilize the CV approach to assess the economic benefits that would follow the expansion of BG use. The CV approach asks respondents a question concerning their WTP using a well-structured survey of randomly chosen consumers.

Some people may doubt the practicality and usefulness of the CV method because it gathers information from a survey of respondents. In this regard, the blue-ribbon National Oceanic and Atmospheric Administration (NOAA) Panel reached the influential conclusion that the CV method can produce reliable quantitative information to be employed in decision making in terms of both public administration and jurisdiction, provided that several guidelines proposed by the NOAA Panel are observed [35,36]. Moreover, following the guidelines can secure the validity and accuracy of the $\mathrm{CV}$ method.

For example, the goods of concern should be familiar to the public, the CV survey should be administered through face-to-face interviews conducted by professionally trained interviewers rather than by telephone or mail, a suitable payment vehicle should be adopted and presented to the respondents, and the substitutes for the goods should be explained to the respondents in the survey. The conditions are met in our study, as will be discussed in detail below.

\subsection{Survey Design Issues}

We commissioned a professional survey firm to arrange a CV field survey. The firm drew a stratified random sample of 1400 households from the Korean national population (18,457,628 households) during April 2014 to obtain information on their WTP for expanding the use of BG and on their socioeconomic characteristics. The firm, Research Prime Service, Inc., is located in Seoul, the capital of Korea, and has a number of experiences of conducting CV surveys. According to '2010 National Population and Housing Census' implemented by the Korea National Statistical Office, there were 18,457,628 households and sixteen provinces in Korea. In order to draw a random sample of this population, sampling was conducted by the professional polling firm. Our sample of 1400 households was allocated to the provinces in proportion to each province's population characteristics, such as age, income, and gender, resulting in 18-328 households being assigned to each province. For example, the numbers of allocated and surveyed households in Seoul, Pusan, Daegu, Incheon, Kwangju, Taejeon, Ulsan, Kyunggi, Kangwon, Chungbuk, Chungnam, Cheonbuk, Cheonnam, Kyungbuk, Kyungnam, and Jeju were 277, 95, 66, 77, 39, 39, 29, 328, 46, 45, 64, $52,56,78,91$, and 18 , respectively.

A CV survey can be conducted using face-to-face, telephone, or mail interviews. The response rate to a mail survey is usually quite low, and a telephone survey can present only a limited volume of information to the respondents. We wished to convey a large amount of explanatory information on BG2, to provide visual cards describing the situation with and without the BG2 policy, and to outline the expected effects of the policy to the respondents in the CV survey $[37,38]$. This is why we chose to hold face-to-face interviews.

We gave the interviewers sufficient information about the purposes and background of the $\mathrm{CV}$ survey and instructed them as to how to answer any questions that might be raised by the interviewees in the CV survey. Moreover, the supervisors affiliated with the survey company trained the interviewers in implementing the CV survey as persuasively and effectively as possible. To ensure 
reliable and responsible decision making by the respondents, 20- to 65-year-old heads of households or homemakers were selected and interviewed for the CV survey.

The survey instrument consists of three parts. The first is an introductory section, providing general background information about BG2 and then asking the respondents about their perceptions of it. For example, the role of biofuel, the definition of BG, the process of producing BG, the environmental merits of BG, the current status of BG in EU and the United States, and the BG2 policy under consideration by the Korean government, which are reported in detail in Section 1, are explained to the respondents. The scenario in which the goods to be valued would be provided to the public should be clearly explained. That is, the main instruments for achieving the improvement goal for the proposed BG2 policy and the expected effects of the policy implementation, which are provided in subsection 2.1, are conveyed to the respondents. The second part includes questions about WTP for introducing the BG2 mandate by 2020 . These questions should be presented in a context that ensures that the WTP questions are plausible, understandable, and meaningful. The final part contains questions relating to the households' socioeconomic variables.

The post-interview follow-up telephone check was done to reduce the number of skipped questions and to verify the results of the survey, both of which tend to increase the reliability of our data. Besides obtaining answers for the skipped variables, a total of 1400 observations verified that the $\mathrm{CV}$ survey was properly conducted. We asked by phone whether the interviewer performed their job properly, whether the interviewers used the visual aids properly, and whether the respondents sufficiently understood the CV questions. We also checked the consistency of the respondent's answers by asking several questions again. Perhaps remarkably, respondents in Korea understood the CV questions easily with the help of the interviewer. In the process of verification, 400 observations from the original total of 1400 interviewed were removed from the sample. For some observations, we could find no one by the given name at the telephone number given by the respondent. For some questionnaires, the answers given over the phone were inconsistent with the answers given in the interview. For some survey results, there were skipped variables that cannot be made up over the phone. Some respondents frankly confessed that they did not pay attention to the CV survey. Some observations were evaluated to be of poor quality by the interviewers. Finally, we obtained 1000 useable observations.

\subsection{The Method of WTP Elicitation}

Our study used a dichotomous choice (DC) question format, which is a type of closed question. This is preferred in the literature to open-ended questions, because a respondent is likely to adopt strategic behavior and have difficulty in giving a WTP response when an open-ended question is asked. In addition, the blue-ribbon NOAA Panel's report [36] supported the use of DC questions rather than open-ended questions. In particular, the single-bounded (SB) DC question or double-bounded (DB) DC question is usually used. The SB DC question is a one-time DC question. By contrast, the DB DC question consists of two DC questions. A respondent who states "yes" to the first bid is additionally asked a follow-up question regarding whether he would pay a second, higher, bid. A respondent who answers "no" to the first bid is additionally asked a follow-up question concerning whether he would pay a second, lower, bid.

The DB DC question format can significantly increase the statistical efficiency compared with the SB DC question format [39]. However, the DB DC question format also augments the response bias when compared with the SB DC question format (e.g., see [40-42]). Thus, SB DC and DB DC questions suffer from low statistical efficiency and high response bias, respectively. As an alternative to them, Cooper et al. [43] suggested the one-and-one-half-bound (OOHB) DC question format. The statistical efficiency of the OOHB DC question format is similar to that of the DB DC question format, and the consistency of the OOHB DC question format is close to that of the SB DC question format.

The OOHB DC question format is based on a set of two bids. In an OOHB DC question, one of two bids is randomly selected by the interviewer, and it is then given to the respondent. If the selected 
bid is the lower one and the respondent's response is "yes", the remaining higher bid is additionally presented to the respondent. If the selected bid is the lower one and the respondent's response is "no", a follow-up question is not needed. If the selected bid is the higher one and the respondent's response is "yes", a follow-up question is needless. If the selected bid is the higher one and the respondent's response is "no", the residual lower bid is then presented to the respondent.

We used seven sets of two bids, which were determined from a pretest with a focus group (30 persons). The list of the sets used in this study is $(1000 ; 3000),(2000 ; 4000),(3000 ; 6000),(4000 ; 8000)$, $(6000 ; 10,000),(8000 ; 12,000)$, and $(10,000 ; 15,000)$; the first element of each set is the lower bid and the second element is the higher bid, and all values are in KRW. At the time of the survey, USD 1 was approximately equal to KRW 1014. The OOHB DC question depends on whether the lower bound of the upper bound bid is randomly chosen as the starting value. The first part is common to both as follows: "The cost of implementing the BG2 policy will be somewhere in the range of lower bid to higher bid Korean won". If the lower bid is chosen as the first bid, then the following question is presented the respondent: "If the cost was [lower bid] Korean won, would your household be willing to pay the amount?" An additional follow-up question is asked only of respondents who answered "Yes" to the question: "And if the cost were [higher bid], would your household still pay it?" If the upper bound bid is chosen the first bid, then the following question is asked: "If the cost were [higher bid], would your household be willing to pay the amount?" An additional follow-up question is asked only of respondents who answered "No" to the question: "And if the cost were [lower bid] instead, would your household still pay it?"

\subsection{Payment Vehicle}

A respondent may have difficulty answering questions asked directly for their WTP because the WTP question uses a hypothetical market. Thus, we should create a believable and meaningful set of questions which simulate a market for the environmental goods in question, with sufficient plausibility that the respondents' answers may be taken as an accurate representation of how they would behave if confronted with an actual market for the goods [44]. Introducing into the survey questionnaire a medium through which the amount would be paid helps the respondent to reveal their true WTP. We usually call the medium the payment vehicle. The payment vehicles found in the literature include taxes, funds, donations, and expenditure. The respondents should feel at home with the payment vehicle, and the goods to be valued should have a clear connection with it. For this reason, a tax is most frequently employed in valuing the economic benefits of the provision of a public goods. There are two options-national and local taxes. Of the two, a national tax is related to expanding the use of BG. Furthermore, among the several types of national tax, income tax is the most familiar to the respondents [45,46]. Therefore, income tax is employed in this study as the payment vehicle.

Next, two points should be decided. One is the frequency of payment, which may be monthly, quarterly, or annual, or the payment may be a one-off payment. Following Egan et al.'s [47] suggestion, we use an annual payment. The other point is the duration of the payment. We decided to use the next ten years. In short, each respondent was asked about whether they would be willing to pay a specified amount annually through higher income tax for the next ten years. The WTP question was as follows: "Is your household willing to pay a given amount for implementing the expansion of BG use through an increase in income tax for next ten years, supposing that the expansion of BG use will certainly succeed?"

Moreover, some additional statements concerning payment were provided in the survey questionnaire. For example, the respondents were told the following: "If a majority of respondents refuse to pay the given amount, the BG2 policy cannot be implemented. However, if a majority of respondents accept the payment, the BG2 mandate can be introduced. Please bear in mind that there are many other policies or projects to be conducted by the Government besides the BG expansion policy". Given that respondents hear that the policy may be implemented if enough people are in favor of it, there may be some concern about strategic behavior in which respondents do not offer their 
true WTP, but free-ride on others' WTP. In order to avoid the problem of strategic behavior, we took two measures. First, we used a DC question format as explained above. Second, we clearly addressed in the survey that, "The amount you indicate will tell us what it is really worth to your household to have the policy implemented. If the policy actually costs less than people are willing to pay, you would only have to pay what it would cost". The information given to respondents about all aspects of the hypothetical market, together with such information as is provided on the good being valued, constitute the framing of the good.

\section{Modeling WTP Responses}

\subsection{The Basic WTP Model}

There are two approaches to modeling WTP responses gathered from a DC CV survey: the utility difference approach suggested by Hanemann [48] and the WTP function approach proposed by Cameron and James [49]. The first specifies the utility difference using a random utility maximization model, while the second specifies the WTP responses directly. As pointed out by McConnell [50], the choice of one out of these two is not an issue of right and wrong but depends on the researcher's preference, because the two approaches are dual in the context of economics. The literature shows that the first has been more frequently applied than the second. Thus, we adopt the utility difference approach in our study. The ratios of "yes" responses to each given bid are the basic input when applying this approach.

Through the process of utility maximization under income constraint, a DC response regarding whether to pay a specified amount for achieving a given environmental improvement or the provision of a public goods is derived for each respondent. The independent variables of the utility function, $U$, include the respondent's income, socioeconomic characteristics, and perceptions about the goods to be valued and their provision state. The provision state of the goods to be valued is $S$. The value of $S$ is one in the case in which the goods are provided and zero otherwise. The respondent's income and the other factors that affect the respondent's utility are $M$ and $T$, respectively. Thus, the utility function is defined as

$$
U=V(S, M ; T)+\omega,
$$

where $V$ is the indirect utility function that we can obtain by inserting the solution to the utility maximization problem into the objective function of the respondent's utility, $\omega$ is a random component of the utility, and $\omega^{\prime}$ s are independent and identically distributed random variables with zero means.

The respondent will maximize their utility by showing their WTP a presented bid, $B$, to obtain the goods to be valued if

$$
V(1, M-B ; T)+\omega_{1} \geq V(0, M ; T)+\omega_{0} .
$$

Rearranging Equation (2) produces

$$
V(1, M-B ; T)-V(0, M ; T) \geq \omega_{0}-\omega_{1}
$$

The left hand side of Equation (3) consists of the utility difference, defined as $\Delta V$, and a systematic and deterministic component, while the right hand side consists of a non-systematic and random component. Let $\omega_{0}-\omega_{1}$ be $\theta$ and $H_{\theta}(\cdot)$ be the cumulative distribution function (cdf) of $\theta$. Using Equation (3), we can express the probability of obtaining the answer "yes" to a given bid as

$$
\operatorname{Pr}\{\text { response is "yes" }\}=\operatorname{Pr}\{\Delta V(B) \geq \theta\}=H_{\theta}[\Delta V(B)] .
$$

From a different perspective, we can introduce the WTP, $X$, as a random variable into the description of the probability of responding "yes" to a presented bid as follows:

$$
\operatorname{Pr}\{\text { response is "yes" }\}=\operatorname{Pr}\{X \geq \theta\}=1-F_{X}(B),
$$


where $F_{X}(\cdot)$ is the cdf of $X$. Thus, comparing Equations (4) and (5) yields

$$
1-F_{X}(B)=H_{\theta}[\Delta V(B)] .
$$

Therefore, there is no need to assume the functional form of $H_{\theta}(\cdot)$; all that is necessary is to assume that of $F_{X}(\cdot)$ and estimate its parameters. Usually, we assume that $\Delta V=\alpha-\beta B$, where $\lambda=(\alpha, \beta)$ is a parameter vector to be estimated.

The assumption of a linear specification means that utility changes due to a change in the bid are independent of income and sociodemographic variables. Of course, the assumption may be restrictive and can be violated. However, checking up independence is too complex and time-consuming to easily work with our data. In practical terms, a linear form should be at least a good approximation of the utility difference. Again, when dealing with DC CV data, the linearity assumption is almost always employed in the literature to reduce the complexity of the analysis procedures. Since the focus of our paper is on showing how our research builds on the existing literature by eliciting household WTP from individuals, it seems unlikely that the main conclusions are affected by this respect.

\subsection{The Model for Dealing with Zero WTP Responses: Spike Model}

Some people can have an interest in the goods to be valued, but others may be totally indifferent to, or place no value on, the goods. In this case, the proportion of zero WTP responses in the CV survey may be high. Researchers should pay close attention to how they deal with observations of WTP responses of zero. For this purpose, we apply the spike model suggested by Kriström [51] and Yoo and Kwak [52]. The spike model specifies the probability of zero WTP responses as a spike at zero in the distribution of the WTP.

The spike model enables us to analyze both zero point and positive interval WTP data in a univariate setting. In the spike model, $F_{X}(B ; \lambda)$ has the following functional form:

$$
F_{X}(B ; \lambda)=\left\{\begin{array}{cl}
{[1+\exp (\alpha-\beta B)]^{-1}} & \text { if } B>0 \\
{[1+\exp (\alpha)]^{-1}} & \text { if } B=0 \\
0 & \text { if } B<0
\end{array} .\right.
$$

Some respondents could have negative WTP if the BG2 policy contributes negatively to their utility. In this regard, we asked the 634 respondents who showed zero WTP a debriefing question of identifying the reasons of zero WTP. The respondents are made up of three groups: true zero WTP, protest bidder, and negative WTP ones. First, some of the respondents having zero WTP stated that the BG2 policy produces no value to them or that they cannot afford to pay the cost. One hundred sixty-eight respondents $(26.5 \%)$ belong to this group. These responses can be interpreted as true zero WTP. Second, some responses indicate protest bidders, which come from 400 respondents $(63.1 \%)$. However, we considered these responses as zero WTP instead of deleting these responses from the dataset for a conservative approach. This may underestimate the mean WTP estimate. Third, 66 respondents (10.4\%) showed negative WTP in that they stated they should be compensated if the policy were implemented. How to deal with the negative WTP responses is a controversial issue. Treating the responses as negative values is not always a panacea because the 'negative' responses may indicate protest bidders rather than true negative WTP. In addition, actual compensation will not be done when the BG2 policy will be implemented. Thus, we decided to handle the negative WTP responses as the zero WTP responses. Of course, we admit that the handling may overestimate the mean WTP estimate. In summary, the BG2 policy is a good to all respondents (89.6\%), and the zero WTP responses were treated as true zero WTP in estimating the spike model.

As explained earlier, the spike is defined as the probability of the respondent's WTP being zero. Thus, the spike is computed as $[1+\exp (\alpha)]^{-1}$. Some covariates, such as the respondent's household income, can be incorporated into the spike model. A common method for achieving this makes the 
covariates penetrate $\alpha$ in Equation (7). That is, $\alpha$ is simply changed into $\alpha+z^{\prime} \delta$, where $z$ is a vector of covariates and $\delta$ is a vector of the corresponding parameters to be estimated.

\subsection{The OOHB DC Model}

As explained above, an OOHB DC model produces a higher level of statistical efficiency than an SB DC model and yields greater consistency than a DB DC model. This is why we use an OOHB DC model in this study instead of an SB or DB DC model. The following OOHB DC model is based on Cooper et al.'s [43] suggestion. We have J observations to be analyzed. A bid, $B_{j}$, is given to respondent $j$ for $j=1, \ldots, J$. During the CV survey, two bids, $B_{j}^{L}$ and $B_{j}^{U}$, where $B_{j}^{L}<B_{j}^{U}$, are presented to each respondent $j$.

About half of the respondents are randomly provided with $B_{j}^{L}$ as the first bid. If the end figure of the respondent's mobile or home phone number is an even number, the lower bid is offered as the starting bid. Otherwise, the higher bid is presented as the starting bid. $B_{j}^{U}$ is supplied as the second bid if the answer is "yes". In this case, there are two outcomes, "yes-yes" $\left(X>B_{j}^{U}\right)$ and "yes-no" $\left(B_{j}^{L}<X<B_{j}^{U}\right)$. If the respondent answers "no" to the first bid, $B_{j}^{L}$, the outcome is "no" $\left(X<B_{j}^{L}\right)$. The remaining respondents are presented with $B_{j}^{U}$ as the first bid. If the answer is "no", the second bid, $B_{j}^{L}$, is sequentially supplied to the respondent and the possible outcomes are "no-yes" $\left(B_{j}^{L}<X<B_{j}^{U}\right)$ and "no-no" $\left(X<B_{j}^{L}\right)$. If the respondent's response is "yes" $\left(X>B_{j}^{U}\right)$, no further bid is required. Therefore, for the six results we can introduce six binary variables, $I_{j}^{Y Y}, I_{j}^{Y N}, I_{j}^{N}, I_{j}^{N Y}, I_{j}^{N N}$, and $I_{j}^{Y}$. The value of each binary variable is one if the respondent's response corresponds to its superscript and zero otherwise. For example, $I_{j}^{Y Y}$ is one if respondent $j$ reports "yes-yes" and zero otherwise.

\subsection{The OOHB DC Spike Model}

In this subsection, we attempt to combine the OOHB DC CV model and the spike model. To identify zero WTP observations, we asked the respondents who gave a "no" response when the first presented bid was $B_{j}^{L}$, or a "no-no" response when the first presented bid was $B_{j}^{U}$, an additional follow-up question that can distinguish true zero WTP from positive WTP. Thus, we could formulate one more binary variable, $I_{j}^{P}$, the value of which is one if the $j$-th respondent's WTP is positive and zero otherwise. The log-likelihood function of the OOHB DC spike model is as follows:

$$
\begin{aligned}
\ln L= & \sum_{j=1}^{J}\left\{\left(I_{j}^{Y Y}+I_{j}^{Y}\right) \ln \left[1-F_{X}\left(B_{j}^{U} ; \lambda\right)\right]\right. \\
& +\left(I_{j}^{Y N}+I_{j}^{N Y}\right) \ln \left[F_{X}\left(B_{j}^{U} ; \lambda\right)-F_{X}\left(B_{j}^{L} ; \lambda\right)\right] . \\
& +I_{j}^{P}\left(I_{j}^{N}+I_{j}^{N N}\right) \ln F_{X}\left(B_{j}^{L} ; \lambda\right) \\
& \left.+\left(1-I_{j}^{P}\right)\left(I_{j}^{N}+I_{j}^{N N}\right) \ln F_{X}(0 ; \lambda)\right\}
\end{aligned}
$$

Using Equation (7), the mean of WTP can be computed as

$$
E(X)=\int_{0}^{\infty}\left[1-F_{X}(B ; \alpha, \beta)\right] d B-\int_{-\infty}^{0} F_{X}(B ; \alpha, \beta) d B=\frac{1}{\beta} \ln [1+\exp (\alpha)]^{-1} .
$$

The middle part of Equation (9) is a conventional formula for estimating the mean using cdf. The first integral is the expected WTP, which is found by integrating a function that gives the probability of "yes" over all non-zero bid values. The second integral is simply equal to 0 since $F_{X}(\cdot)=0$ for these values of $B$. 


\section{Results and Discussion}

\subsection{Data}

As explained above, we obtained 1000 useable observations. Definitions and sample statistics of some variables are presented in Table 1. We need to check that our sample is representative of the Korean population. Of the five variables, the values for gender, family, and income were available from the Korea National Statistical Office. Accordingly to the Korea National Statistical Office, the ratio of male people, the average of the household size, and the average of household income are $50.0 \%, 2.76$ persons, and KRW 4.28 million, respectively, at the time of the survey. These values are quite close to the sample means (50.0\%, 3.34 persons, and 420.32 ten thousand Korean won). Thus, we can conclude that our sample is representative of the national population.

Table 1. Definitions and sample statistics of the variables.

\begin{tabular}{cccc}
\hline Variable & Definition & Mean & Standard Deviation \\
\hline gender & The respondent's gender $(0=$ female; $1=$ male) & 0.50 & 0.50 \\
\hline age & The respondent's age in years & 44.78 & 1.09 \\
\hline family & The size of the respondent's household (unit: persons) & 3.34 & 228.96 \\
\hline income & $\begin{array}{c}\text { The household's monthly income before tax deduction } \\
\text { (unit: ten thousand Korean won = USD 9.11) }\end{array}$ & 420.32 & 14.13 \\
\hline education & The respondent's education level in years & 2.37 \\
\hline
\end{tabular}

Table 2 describes the distribution of responses by each bid amount. Each set of bids was allocated to a similar number of respondents, as is shown in the last column of Table 2. Both "no-no" responses when the lower bid was presented as the first bid and "no-no-no" responses when the upper bid was presented as the first bid indicate the zero WTP responses. A total of 634 households (63.4\%) revealed zero WTP for implementing the expansion of BG use. This implies that the use of the spike model to deal with zero WTP responses is a suitable approach in our study. Overall, the proportion of "yes" responses to a given bid declines as the magnitude of the bid increases. For instance, when the lower bid is presented as the first bid, that is, "from lower bid to upper bid", 26 respondents (36.1\%) accepted the payment of KRW 1000 (USD 1.0), while just 6 respondents (8.4\%) agreed to the payment of KRW 10,000 (USD 9.9).

\subsection{Estimation Results of the OOHB DC Spike Model}

The estimation results of the OOHB DC spike model are reported in Table 3. The parameter estimates can be obtained by finding the parameter values maximizing Equation (8), in other words, by applying the maximum likelihood estimation method. As explained above, $\alpha$ and $\beta$ re the parameters, which penetrate into the utility function, to be estimated and determine the shape of the cdf of WTP. In particular, $\beta$ should be a positive real number because the higher the bid is, the lower the utility is. All the estimates for two parameters, $\alpha$ and $\beta$, are statistically significant at the $1 \%$ level. Moreover, the null hypothesis that the parameter estimates are all zero can be rejected at the $1 \%$ level, since the $p$-value for the Wald statistic calculated under the null hypothesis is less than 0.01 . In particular, the estimate for the spike is 0.635 , which perfectly coincides with the sample proportion of the zero WTP responses provided in Table 2. This indicates that the spike model employed here fits our data well. 
Table 2. Distribution of the responses by the bid amount.

\begin{tabular}{|c|c|c|c|c|c|c|c|c|c|c|c|}
\hline \multicolumn{7}{|c|}{ Lower Bid Is Presented as the First Bid (\%) ${ }^{b}$} & \multicolumn{5}{|c|}{ Upper Bid Is Presented as the First Bid (\%) ${ }^{b}$} \\
\hline \multicolumn{2}{|c|}{ Bid Amount $^{a}$} & "Yes-Yes" & "Yes-No" & “No-Yes" & "No-No" & Totals & "Yes" & “No-Yes" & “No-No-Yes" & "No-No-No" & Totals \\
\hline 1000 & 3000 & $10(13.9)$ & $16(22.2)$ & $2(2.8)$ & $44(61.1)$ & $72(100)$ & $16(22.5)$ & $9(12.7)$ & $5(7.0)$ & $41(57.7)$ & $71(100)$ \\
\hline 2000 & 4000 & $8(11.3)$ & $9(12.7)$ & $11(15.5)$ & $43(60.6)$ & $71(100)$ & $15(20.8)$ & $8(11.1)$ & $6(8.3)$ & $43(59.7)$ & $72(100)$ \\
\hline 3000 & 6000 & $7(9.9)$ & $12(16.9)$ & $4(5.6)$ & 48 (67.6) & $71(100)$ & $13(18.1)$ & $6(8.3)$ & $6(8.3)$ & 47 (65.3) & $72(100)$ \\
\hline 4000 & 8000 & $6(8.3)$ & 14 (19.4) & $6(8.3)$ & 46 (63.9) & $72(100)$ & $16(22.5)$ & $6(8.5)$ & $4(5.6)$ & $45(63.4)$ & $71(100)$ \\
\hline 6000 & 10,000 & $3(4.2)$ & $6(8.5)$ & 14 (19.7) & 48 (67.6) & $71(100)$ & 7 (9.9) & $3(4.2)$ & 14 (19.7) & 47 (66.2) & $71(100)$ \\
\hline 8000 & 12,000 & $3(4.2)$ & $8(11.3)$ & $16(22.5)$ & $44(62.0)$ & $71(100)$ & $7(9.9)$ & $6(8.5)$ & $17(23.9)$ & $41(57.7)$ & $71(100)$ \\
\hline 10,000 & 15,000 & $2(2.8)$ & $4(5.6)$ & 14 (19.4) & $52(72.2)$ & $72(100)$ & $8(11.1)$ & $4(5.6)$ & 15 (20.8) & $45(62.5)$ & $72(100)$ \\
\hline \multicolumn{2}{|c|}{ Totals } & $39(7.8)$ & 69 (13.8) & 67 (13.4) & $325(65.0)$ & $500(100)$ & $82(16.4)$ & $42(8.4)$ & 67 (13.4) & $309(61.8)$ & $500(100)$ \\
\hline
\end{tabular}

Notes: ${ }^{a}$ The unit is the Korean won; ${ }^{b}$ The numbers in parentheses below the number of responses are the percentage of the sample size. 
Table 3. Estimation results of the spike model.

\begin{tabular}{|c|c|}
\hline Variables & Estimates $^{d}$ \\
\hline Constant & $-0.553(-8.43) \#$ \\
\hline $\mathrm{Bid}^{\mathrm{a}}$ & $-0.179(-17.23) \#$ \\
\hline Spike & $0.635(41.75)^{\#}$ \\
\hline Mean WTP per household per year & KRW 2539 (USD 2.5) \\
\hline$t$-value & $14.41^{\#}$ \\
\hline $95 \%$ confidence interval $b$ & KRW 2231 to 2920 (USD 2.2 to 2.8 ) \\
\hline $99 \%$ confidence interval ${ }^{b}$ & KRW 2125 to 3047 (USD 2.1 to 2.9) \\
\hline Number of observations & 1000 \\
\hline Log-likelihood & -1050.06 \\
\hline Wald statistic ( $p$-value $)^{c}$ & $247.03(0.000)$ \\
\hline \multicolumn{2}{|c|}{$\begin{array}{l}\text { Notes: }{ }^{a} \text { The unit is } 1000 \text { Korean won, and USD } 1.0 \text { was approximately equal to KRW } 1014 \text { at the time of } \\
\text { the survey; }{ }^{b} \text { The confidence intervals are calculated by the use of the Monte Carlo simulation technique of } \\
\text { Krinsky and Robb [53] with } 5000 \text { replications; }{ }^{c} \text { The null hypothesis is that all the parameters are jointly zero } \\
\text { and the corresponding } p \text {-value is reported in the parentheses beside the statistic; }{ }^{\mathrm{d}} \text { The numbers in parentheses } \\
\text { beside the coefficient estimates are } t \text {-values computed from the analytic second derivatives of the log-likelihood; } \\
\# \text { indicates statistical significance at the } 1 \% \text { level. }\end{array}$} \\
\hline
\end{tabular}

Using Equation (9) and the values presented in the upper panel of Table 3, we can obtain an estimate of the mean WTP of KRW 2539 (USD 2.5) per household per year. Its $t$-value is 14.41; thus, the estimate is statistically meaningful at the $1 \%$ level. To handle the uncertainty related to the computation of the estimate, we try to report the confidence intervals for the estimate. For this purpose, the parametric bootstrapping method proposed by Krinsky and Robb [53] is the most widely employed in the literature. Thus, we also use the method with 5000 replications to obtain the $95 \%$ and $99 \%$ confidence intervals, which are contained in Table 3. The 95\% confidence interval is tighter than the $99 \%$ confidence interval.

\subsection{The Estimation Results of the OOHB DC Spike Model with Covariates}

We seek to estimate the spike model with covariates explained in Section 3.2. Some variables used for the covariates are defined in Table 1 . They are related to the characteristics of the respondent or the respondent's household. Furthermore, the sample statistics of the covariates are reported in Table 3. The model contains a total of five variables. The sample characteristics appear to reflect those of the population well, since we drew a random sample of Korean households with the help of a professional polling firm. Randomness of the sample could provide evidence that the sociodemographic makeup of their sample is similar to that of the Korean population. The results from the estimation of the spike model including the variables shown in Table 1 are described in Table 4.

Table 4. Estimation results of the spike model with covariates.

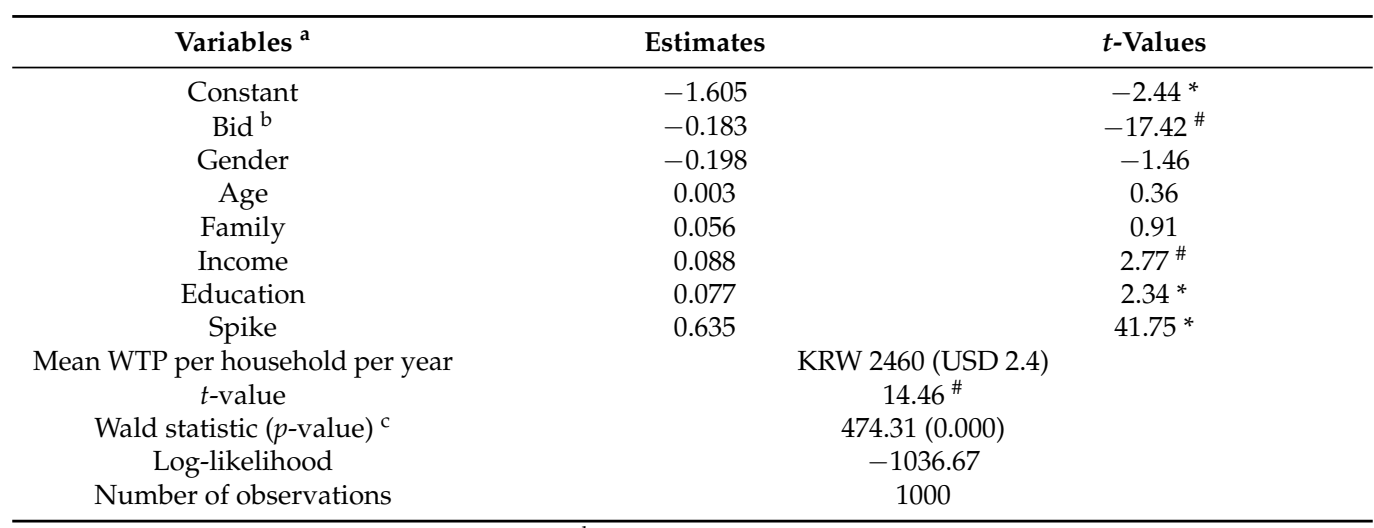

Notes: ${ }^{\mathrm{a}}$ The variables are defined in Table $1{ }^{\mathrm{b}}$ The unit is 1000 Korean won and USD 1.0 was approximately equal to KRW 1014 at the time of the survey; ${ }^{\mathrm{c}}$ The null hypothesis is that all the parameters are jointly zero, and the corresponding $p$-value is reported in the parentheses beside the statistic; * and \# indicate statistical significance at the $5 \%$ and $1 \%$ levels, respectively. 
In particular, the coefficient estimates for income and education in the model are statistically significant at the $1 \%$ and $5 \%$ levels, respectively. The finding that the coefficient estimates for income and education have a positive sign indicates that the respondents with a higher income and higher level of education have a tendency to respond "yes" to a given bid. In order to deal with the WTP data with too many zeros, we applied the spike model rather than the conventional model. The spike model can be easily specified for the utility difference approach. However, the spike model cannot be specified for the WTP function approach where we can test whether some covariates have an impact on WTP instead of the probability of saying "yes" to a given bid. For this reason, any spike model for the WTP function approach is not found in the literature. Thus, we estimate the yearly mean WTPs by a group of covariates and report them in Table 5 to capture heterogeneity among the population.

Table 5. Yearly mean willingness to pay estimates per household by group of covariates.

\begin{tabular}{cccccccc}
\hline \multicolumn{2}{c}{ Gender $^{\text {a }}$} & \multicolumn{2}{c}{ Age $^{\text {a }}$} & \multicolumn{2}{c}{ Income $^{\text {a }}$} & \multicolumn{2}{c}{ Education $^{\text {a }}$} \\
\hline Male & Female & Younger & Older & Lower & Higher & Lower & Higher \\
\hline KRW 2272 & KRW 2664 & KRW 2464 & KRW 2344 & KRW 1724 & KRW 2493 & KRW 2078 & KRW 2604 \\
(USD 2.2) & (USD 2.6) & (USD 2.4) & (USD 2.3) & (USD 1.7) & (USD 2.5) & (USD 2.1) & (USD 2.6) \\
\hline
\end{tabular}

Notes: ${ }^{\text {a }}$ The variables are defined in Table 1; Younger (Lower) and older (Higher) mean the group whose value is less and more, respectively, than the sample averages presented in Table 1.

\subsection{Discussion of the Results}

As the final step of our study, expanding the household value to the national population is useful for enabling the results to be used in BG-related policy making and decision making. To obtain an estimate of the total public WTP, we need to use the mean WTP estimate obtained from the investigation of the sample observations and the information on population size. During this process, the most important issue is whether the sample is representative of the population or not. As addressed above, the sampling was conducted by a professional survey firm to secure randomness of the sampling and consistency with the characteristics of the population. Another important issue is the response rate to the $\mathrm{CV}$ survey. Our CV survey was implemented using in-person face-to-face interviewing; thus, the response rate was almost 100\%. Moreover, as discussed in subsection 4.1, the sample characteristics are not significantly different from the population ones. Thus, we cannot deny that our sample is representative of the national population.

We use the mean WTP estimate from the model with no covariates, since setting the covariates may influence the mean WTP value if we use the mean WTP value from the model with covariates. According to Statistics Korea (http://kosis.kr) [54], the number of households was 18,457,628 at the time of the survey, April 2014. Using this information, expanding the value to the national population gives us KRW 46.9 billion (USD 45.3 million) per year. The present value of the total external benefits amounts to KRW 372.7 billion (USD 368.4 million) using a social discount rate of 5.5\%. To examine the economic feasibility of the BG2 policy, we can compare this value with the cost involved in implementing the BG2 policy. The corresponding $95 \%$ and $99 \%$ confidence intervals for the total external benefits are KRW 327.5 to 428.6 billion (USD 323.7 to 423.7 million) and KRW 311.9 to 447.2 billion (USD 308.4 to 442.1 million), respectively. Overall, we can judge that Korean households are ready to bear a share of the financial burden of implementing the BG2 mandate.

One more point should be addressed here in the context of interpreting the results. Our study estimated the household WTP for implementation of a new regulation through higher income tax as a payment vehicle. However, there is no notion of changes in fuel prices or quantity supplied under the new program, which will also impact consumption benefits. If consumers are fully aware of cost increases, then they are willing to pay the hypothetical income tax in addition to a higher price for fuel. 


\section{Conclusions}

GHG is well known for causing global climate change, and its emission is continuously observed as a result of human activities. Countries have agreed to outline publicly the post-2020 climate actions that they intend to take under a new international agreement known as their intended nationally determined contributions (INDCs). Korea's INDCs feature a reduction of its GHG emissions by $37 \%$ from the business-as-usual level by 2030 across all economic sectors [55]. One of the effective alternatives for achieving this target is to expand the use of renewable energy sources. Internationally aligned schemes for BG will be vital to ensure a positive environmental and social impact and create an international market for sustainability. Furthermore, the Korean Government plans to implement the BG2 policy until 2020. Because it will raise the production cost of fuel and consequently incur a rise in its price, the public acceptability of the BG2 program should be investigated.

This study attempted to assess the public's WTP for introducing the BG2 program in Korea using the CV approach. An OOHB DC question was used to reduce the response bias as well as to increase the statistical efficiency, and the spike model was applied to handle the zero WTP data explicitly. Overall, the CV survey was successful in eliciting the additional WTP values from the respondents. We found that the mean WTP for introducing the BG3 mandate was estimated to be KRW 2539 (USD 2.5) per household per year for the next 10 years, and this value is significantly different from zero at the $1 \%$ level. We can conclude that Korean households are ready to shoulder some of the financial burden of introducing the BG2 mandate to expand the use of BG.

Expanding the value to the national population gives us KRW 46.9 billion (USD 45.3 million) per year. The present value of the implementation of the expansion was computed as KRW 372.7 billion (USD 368.4 million) using a social discount rate of $5.5 \%$, which has been officially announced and is currently being adopted by the Korean Government. This value can be compared with the costs of implementing the BG2 policy. If the former is greater than the latter, the BG2 program can be well established. Unfortunately, to the best of the authors' knowledge, there is no available data on the cost of the proposed BG program. Thus, as a second stage of this study, measuring the cost would be meaningful. It would be interesting to know if the WTP of the population is on the same order of magnitude as the costs of such a policy.

Acknowledgments: This is a research supported by Sudokwon Landfill Site Management Corporation as a part of its 2016 Human Resource Training Program.

Author Contributions: All the authors contributed immensely. Ho-Young Kim designed the ideas and analyzed the data; So-Yeon Park wrote the majority of the manuscript; Seung-Hoon Yoo contributed the main idea and various scientific insights and helped to edit the manuscript.

Conflicts of Interest: The authors declare no conflict of interest.

\section{References}

1. Krich, K.; Augenstein, D.; Batmale, J.P.; Benemann, J.; Rutledge, B.; Salour, D. Biomethane from Dairy Waste; Western United Dairymen: Modesto, CA, USA, 2005.

2. Muradin, M.; Foltynowicz, Z. Potential for producing biogas from agricultural waste in rural plants in Poland. Sustainability 2014, 6, 5065-5074. [CrossRef]

3. Torquati, B.; Venanzi, S.; Ciani, A.; Diotallevi, F.; Tamburi, V. Environmental sustainability and economic benefits of dairy farm biogas energy production: A case study in Umbria. Sustainability 2014, 6, 6696-6713. [CrossRef]

4. United States Environmental Protection Agency. EPA Finalizes 2013 Renewable Fuel Standards \& EPA Finalizes 2012 Renewable Fuel Standards; United States Environmental Protection Agency: Washington, DC, USA, 2013.

5. Global Subsidies Initiative. Biofuels - At What Cost? Mandation Ethanol and Biodiesel Consumption in Germany; Global Subsidies Initiative: Geneva, Switzerland, 2012.

6. Joe, J.H.; Lee, H.S.; Yang, E.M. A Foreign Case Study of Renewable Fuel Standard with Respect to Bio-Gas; Korea Environment Institute: Sejong City, Korea, 2013.

7. Hite, D.; Duffy, P.; Bransby, D.; Slaton, C. Consumer willingness-to-pay for biopower: Results from focus groups. Biomass Bioenergy 2008, 32, 11-17. [CrossRef] 
8. Soliño, M.; Prada, A.; Vázquez, M.X. Designing a forest-energetic policy to reduce forest fires in Galicia (Spain): A contingent valuation application. J. For. Econ. 2010, 16, 217-233.

9. Solomon, B.D.; Johnson, N.H. Valuing climate protection through willingness to pay for biomass ethanol. Ecol. Econ. 2009, 68, 2137-2144. [CrossRef]

10. Petrolia, D.R.; Bhattacharjee, S.; Hudson, D.; Hemdon, C.W. Do Americans want ethanol? A comparative contingent-valuation study of willingness to pay for E-10 and E-85. Energy Econ. 2010, 32, 121-128. [CrossRef]

11. Savvanidou, E.; Zervas, E.; Tsagarakis, K.P. Public acceptance of biofuels. Energy Policy 2010, 38, $3482-3488$. [CrossRef]

12. Cicia, G.; Cembalo, L.; Giudice, T.D.; Palladino, A. Fossil energy versus nuclear, wind, solar and agricultural biomass: Insights from an Italian national survey. Energy Policy 2012, 42, 59-66. [CrossRef]

13. Lanzini, P.; Testa, F. Factors affecting drivers' willingness to pay for biofuels: The case of Italy. J. Clean. Prod. 2016, 112, 2684-8692. [CrossRef]

14. Saz-Salazar, S.; Hernández-Sancho, F.; Sala-Garrido, R. The social benefits of restoring water quality in the context of the Water Framework Directive: A comparison of willingness to pay and willingness to accept. Sci. Total Environ. 2009, 407, 4574-4583. [CrossRef] [PubMed]

15. Saverio, M.; Fabrizio, F.; Rocco, M. Social evaluation approaches in landscape projects. Sustainability 2014, 6, 7906-7920.

16. Huang, C.H.; Wang, C.H. Estimating the total economic value of cultivated flower land in Taiwan. Sustainability 2015, 7, 4764-4782. [CrossRef]

17. Harun, R.; Muresan, I.C.; Arion, F.H.; Dumitras, D.E.; Lile, R. Analysis of factors that influence the willingness to pay for irrigation water in the Kurdistan regional government, Iraq. Sustainability 2015, 7, 9574-9586. [CrossRef]

18. Schkade, D.A.; Payne, J.W. How people respond to contingent valuation questions: A verbal protocol analysis of willingness to pay for an environmental regulation. J. Environ. Econ. Manag. 1994, 26, 88-109. [CrossRef]

19. Cameron, T.A.; Englin, J. Respondent experience and contingent valuation of environmental goods. J. Environ. Econ. Manag. 1997, 33, 296-313. [CrossRef]

20. Smith, V.K.; Osborne, L.L. Do contingent valuation estimates pass a "scope" test? A meta-analysis. J. Environ. Econ. Manag. 1996, 31, 287-301. [CrossRef]

21. Chien, Y.-L.; Huang, C.J.; Shaw, D. A general model of starting point bias in double-bounded dichotomous contingent valuation surveys. J. Environ. Econ. Manag. 2005, 50, 362-377. [CrossRef]

22. Buschena, D.E.; Anderson, T.L.; Leonard, J.L. Valuing non-marketed goods: The case of elk permit lotteries. J. Environ. Econ. Manag. 2001, 41,33-43. [CrossRef]

23. Parsons, G.R.; Myers, K. Fat tails and truncated bids in contingent valuation: An application to an endangered shorebird species. Ecol. Econ. 2016, 129, 210-219. [CrossRef]

24. Whitehead, J.C. Plausible responsiveness to scope in contingent valuation. Ecol. Econ. 2016, 128, 17-22. [CrossRef]

25. Da Costa, C.A.; Santos, J.L. Estimating the demand curve for sustainable use of pesticides from contingent-valuation data. Ecol. Econ. 2016, 127, 121-128. [CrossRef]

26. Gelo, D.; Koch, S.F. Contingent valuation of community forestry programs in Ethiopia: Controlling for preference anomalies in double-bounded CVM. Ecol. Econ. 2015, 114, 79-89. [CrossRef]

27. Lo, A.Y.; Jim, C.Y. Protest response and willingness to pay for culturally significant urban trees: Implications for Contingent Valuation Method. Ecol. Econ. 2015, 114, 58-66. [CrossRef]

28. Börger, T. Keeping up appearances: Motivations for socially desirable responding in contingent valuation interviews. Ecol. Econ. 2013, 87, 155-165. [CrossRef]

29. Longo, A.; Hoyos, D.; Markandya, A. Sequence effects in the valuation of multiple environmental programs using the contingent valuation method. Land Econ. 2015, 91, 20-35. [CrossRef]

30. Bateman, I.J.; Munro, A.; Poe, G.L. Decoy Effects in Choice Experiments and Contingent Valuation: Asymmetric Dominance. Land Econ. 2008, 84, 115-127. [CrossRef]

31. Champ, P.A.; Flores, N.E.; Brown, T.C.; Chivers, J. Contingent Valuation and Incentives. Land Econ. 2002, 78, 591-604. [CrossRef]

32. Svedsäter, H. Economic Valuation of the Environment: How Citizens Make Sense of Contingent Valuation Questions. Land Econ. 2003, 79, 122-135. [CrossRef] 
33. Desvousges, W.; Mathews, K.; Train, K. An adding-up test on contingent valuations of river and lake quality. Land Econ. 2015, 91, 556-571. [CrossRef]

34. Carson, R.; Hanemann, M. Ch 17 Contingent Valuation. In Handbook of Environmental Economics, Volume 2: Valuing Environmental Changes, 1st ed.; Mäler, K.G., Vincent, J.R., Eds.; North Holland: Amsterdam, The Netherlands, 2006; pp. 821-936.

35. Carson, R.T.; Mitchell, R.C.; Hanemann, M.; Kopp, R.J.; Presser, S.; Ruud, P.A. Contingent valuation and lost passive use: Damages from the Exxon Valdez oil spill. Environ. Resour. Econ. 2003, 25, 257-286. [CrossRef]

36. Arrow, K.; Solow, R.; Portney, P.R.; Leamer, E.E.; Radner, R.; Schuman, H. Report of the NOAA panel on contingent valuation. Fed. Regist. 1993, 58, 4601-4614.

37. Yoo, S.H.; Kwak, S.Y. Willingness to pay for green electricity in Korea. Energy Policy 2009, 37, 5408-5416. [CrossRef]

38. Ezebilo, E. Willingness to pay for improved residential waste management in a developing country. Int. J. Environ. Sci. Technol. 2013, 10, 413-422. [CrossRef]

39. Hanemann, W.M.; Loomis, J.; Kanninen, B.J. Statistical efficiency of double-bounded dichotomous choice contingent valuation. Am. J. Agric. Econ. 1991, 73, 1255-1263. [CrossRef]

40. McFadden, D. Contingent valuation and social choice. Am. J. Agric. Econ. 1994, 76, 689-708. [CrossRef]

41. Bateman, I.J.; Langford, L.H.; Jones, P.; Kerr, G.N. Bound and path effects in double and triple bounded dichotomous choice contingent valuation. Resour. Energy Econ. 2001, 23, 191-213. [CrossRef]

42. Carson, R.T.; Groves, T. Incentive and informational properties of preference questions. Environ. Resour. Econo. 2007, 37, 181-210. [CrossRef]

43. Cooper, J.C.; Hanemann, M.; Signorello, G. One-and-one-half-bound dichotomous choice contingent valuation. Rev. Econ. Stat. 2002, 84, 742-750. [CrossRef]

44. Mitchell, R.C.; Carson, R.T. Using Surveys to Value Public Goods: The Contingent Valuation Method; Resources for the Future: Washington, DC, USA, 1989.

45. Park, S.Y.; Yoo, S.H.; Kwak, S.J. The conservation value of Shinan Tidal Flat in Korea: A contingent valuation study. Int. J. Sust. Dev. World Ecol. 2013, 20, 54-62. [CrossRef]

46. Lee, M.K.; Yoo, S.H. Public's willingness to pay for a marina port in Korea: A contingent valuation study. Ocean Coast. Manag. 2016, 119, 119-127. [CrossRef]

47. Egan, K.J.; Corrigan, J.R.; Dwyer, D.F. Three reasons to use annual payments in contingent valuation surveys: Convergent validity, discount rates, and mental accounting. J. Environ. Econ. Manag. 2015, 72, 123-136. [CrossRef]

48. Hanemann, W.M. Welfare evaluations in contingent valuation experiments with discrete responses. Am. J. Agric. Econ. 1984, 66, 332-341. [CrossRef]

49. Cameron, T.A.; James, M.D. Efficient estimation methods for "closed-ended" contingent valuation surveys. R. Econ. Stat. 1987, 69, 269-276. [CrossRef]

50. McConnell, K.E. Models for referendum data: The structure of discrete choice models for contingent valuation. J. Environ. Econ. Manag. 1990, 18, 19-34. [CrossRef]

51. Kriström, B. Spike models in contingent valuation. Am. J. Agric. Econ. 1997, 79, 1013-1023. [CrossRef]

52. Yoo, S.H.; Kwak, S.J. Using a spike model to deal with zero response data from double bounded dichotomous choice contingent valuation surveys. Appl. Econ. Lett. 2002, 9, 929-932. [CrossRef]

53. Krinsky, I.; Robb, A.L. On approximating the statistical properties of elasticities. Rev. Econ. Stat. 1986, 68, 715-719. [CrossRef]

54. Korean Statistical Information Service. Available online: http://www.kosis.kr (accessed on 15 August 2016).

55. Korea Government. Intended Nationally Determined Contribution Submitted by the Republic of Korea. Available online: http://www4.unfccc.int/submissions/INDC/Published\%20Documents/Republic\%20of\% 20Korea/1/INDC\%20Submission\%20by\%20the\%20Republic\%20of\%20Korea\%20on\%20June\%2030.pdf (accessed on 15 October 2015).

(C) 2016 by the authors; licensee MDPI, Basel, Switzerland. This article is an open access article distributed under the terms and conditions of the Creative Commons Attribution (CC-BY) license (http://creativecommons.org/licenses/by/4.0/). 